\title{
Whipple Disease Diagnosed with PCR Using Formalin-fixed Paraffin-embedded Specimens of the Intestinal Mucosa
}

\author{
Nobuhisa Yajima ${ }^{1}$, Ryuichi Wada ${ }^{1}$, Sotai Kimura ${ }^{1}$, Yutaka Matsuzaki ${ }^{1}$, Daisuke Chiba ${ }^{2}$, \\ Yoshihito Ebina ${ }^{3}$, Kiyofumi Ohkusu ${ }^{4}$ and Soroku Yagihashi ${ }^{1}$
}

\begin{abstract}
We herein present the case of a 54-year-old Japanese woman with Whipple disease diagnosed with polymerase chain reaction (PCR) using formalin-fixed paraffin-embedded (FFPE) specimens. The patient complained of weight loss, diarrhea and arthralgia. An endoscopic examination revealed swollen villi in the duodenum and ileum. Pathology demonstrated the presence of numerous macrophages filled with diastaseresistant PAS-positive particles. PCR using FFPE specimens amplified a fragment of $16 \mathrm{~S}$ rDNA from Tropheryma whipplei. After the administration of ceftriaxone followed by trimethoprim/sulfamethoxazole, no signs of recurrence were observed for two years. The use of FFPE specimens for PCR should be considered for the prompt diagnosis and prevention of disease progression.
\end{abstract}

Key words: Whipple disease, formalin-fixed paraffin-embedded specimen, PCR, 16S rDNA, sequence

(Intern Med 52: 219-222, 2013)

(DOI: 10.2169/internalmedicine.52.8642)

\section{Introduction}

Whipple disease (WD) is a chronic inflammatory disease caused by the Gram-positive bacillus Tropheryma whipplei $(1,2)$. The microorganism affects multiple organs such as the gastrointestinal tract, heart, lungs and central nervous system (CNS). The bacillus is identified as diastase-resistant periodic acid-Schiff (PAS)-positive particles in macrophages. A definitive diagnosis requires the identification of $T$. whipplei on immunostaining, electron microscopy or a polymerase chain reaction (PCR) analysis of the microorganism's genes. Fresh tissues are usually used for PCR analyses. We herein report a case of WD in which the diagnosis was confirmed with a PCR analysis using formalin-fixed paraffinembedded (FFPE) specimens biopsied from intestinal tissues.

\section{Case Report}

\section{Clinical history}

A Japanese woman 54 years of age complained of persistent fever and arthralgia of the hand joints. She also presented with diarrhea occurring four times a day and had lost $6 \mathrm{~kg}$ of weight over the previous six months. The cervical, axillary and inguinal lymph nodes were swollen. The laboratory data revealed anemia $(\mathrm{Hb}: 7.6 \mathrm{~g} / \mathrm{dL}$ ) and leukocytosis (WBC: $11,700 / \mu \mathrm{L}$ ), and the CRP level was elevated at 5.42 $\mathrm{mg} / \mathrm{dL}$. All tests for viral antigens such as HBV, HCV, HIV and HTLV-1 were negative. The patient had no remarkable family history. She had lived in France in her twenties. CT showed splenomegaly and swollen lymph nodes in the mediastinum, mesentery and retroperitoneum. A small amount of pericardial and pleural effusions was also noted.

An endoscopic examination of the upper gastrointestinal tract and colon revealed swollen villi approximately $1 \mathrm{~mm}$ in diameter in the duodenum and ileum (Fig. 1A-C). In the

\footnotetext{
${ }^{1}$ Department of Pathology and Molecular Medicine, Hirosaki University Graduate School of Medicine, Japan, ${ }^{2}$ Department of Internal Medicine, Kensei Hospital, Japan, ${ }^{3}$ Department of Pathology, Kensei Hospital, Japan and ${ }^{4}$ Department of Microbiology, Regeneration and Advanced Medical Science, Gifu University Graduate School of Medicine, Japan

Received for publication July 20, 2012; Accepted for publication August 21, 2012

Correspondence to Dr. Ryuichi Wada, ryuichi@cc.hirosaki-u.ac.jp
} 


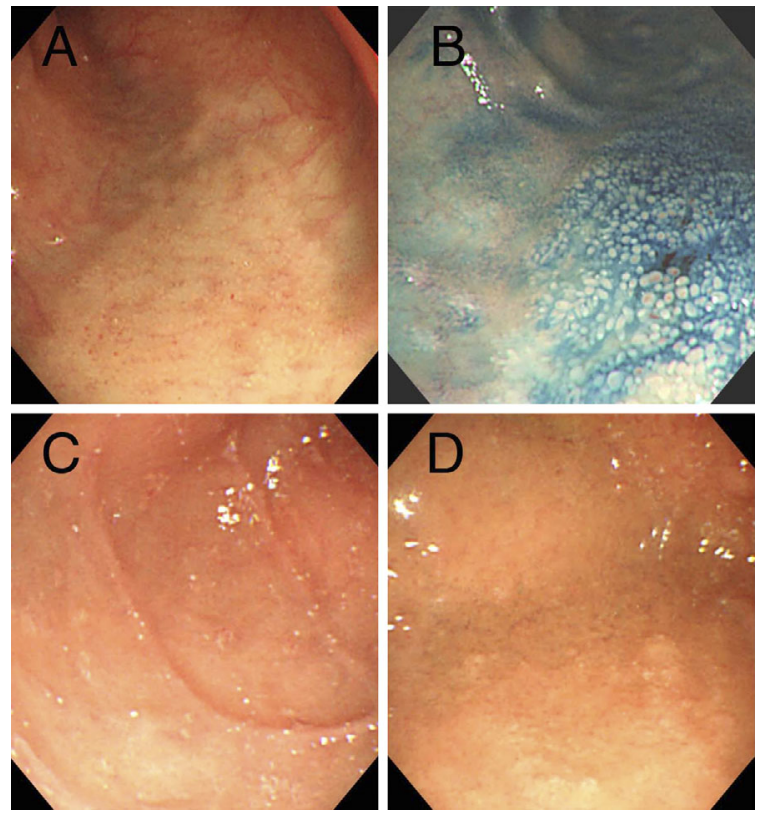

Figure 1. Endoscopic findings. (A-C) Images obtained during the initial endoscopic examination of the ileum (A), ileum with indigo carmine (B) and duodenum $(C)$. Sheet-like aggregation of dilated villi was evident in the ileum; however, dilated villi were only sparsely found in the duodenum. (D) Image of the duodenum obtained during the follow-up endoscopic examination performed three months after treatment.

terminal ileum, the villi formed a coral reef-like lesion (Fig. 1A, B). Biopsy specimens taken from the duodenum and ileum were fixed in formalin and subjected to a pathological examination. Based on the pathology and a PCR analysis of T. whipplei $16 \mathrm{~S}$ rDNA, a diagnosis of WD was made. Antibiotic therapy was initiated with administration of ceftriaxone (CTRX) 2 g/day for two weeks followed by 320 $\mathrm{mg}$ of trimethoprim and 1,600 $\mathrm{mg}$ of sulfamethoxazole (TMP/SMZ) daily. The patient's general condition improved; however, her fever remained. Thick villi were still present in the duodenum on an endoscopic examination performed three months after treatment (Fig. 1D). The villi returned to normal one year after treatment. The results of PCR analyses of $T$. whipplei $16 \mathrm{~S}$ rDNA performed at three months and one year were negative. Treatment with TMP/ SMZ was discontinued after one year, and there has been no exacerbation of the disease for two years.

\section{Pathological findings}

The biopsy specimens were fixed in $10 \%$ buffered formalin and embedded in paraffin. Four- $\mu$ m-thick sections were stained with Hematoxylin and Eosin (H\&E), periodic acidSchiff (PAS), Warthin-Starry and acid-fast stainings.

On the H\&E sections, there appeared many polypoid projections of thick villi in the mucosa of the duodenum and ileum (Fig. 2A). Aggregation of foamy macrophages was noted in the lamina propria of the mucosa and submucosa of the villi (Fig. 2B). Numerous diastase-resistant PAS-positive particles were present in the cytoplasm of the macrophages

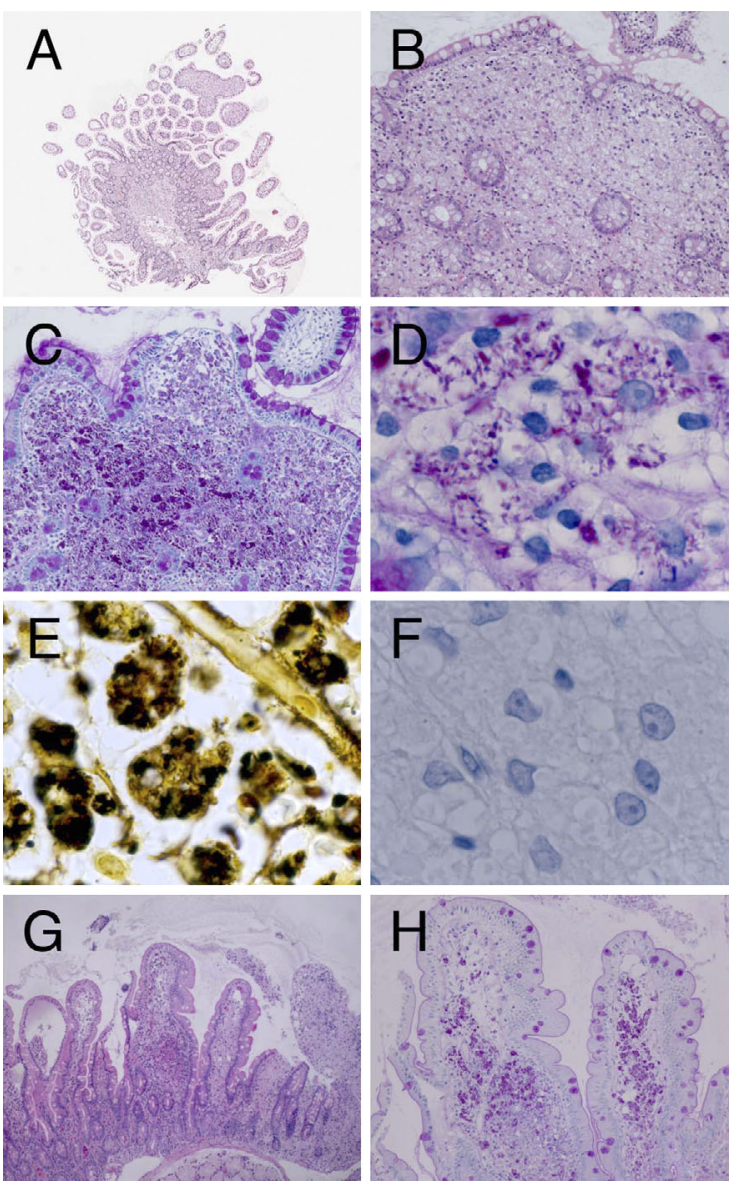

Figure 2. Histology of the biopsy specimens. (A) A biopsy specimen of the duodenum with dilated villi. (B) Aggregation of foamy macrophages in the lamina propria. (C) Diastase-resistant-positive particles found in the cytoplasm of foamy macrophages. (D) High magnification of a PAS stain (D), a Warthin-Starry stain (E) and an acid-fast stain (F). (G-H) Histology of the biopsy specimens of the duodenum obtained during the follow-up endoscopic examination performed three months after treatment. (G) Duodenal mucosa with slightly swollen villi. (H) Diastase-resistant PAS-positive particles remaining in the cytoplasm of foamy macrophages. (Original magnification; A: $\times 10 . \mathrm{B}, \mathrm{C}: \times 100 . \mathrm{D}-\mathrm{F}: \times 400 . \mathrm{G}: \times 40 . \mathrm{H}$ : $\times 100$ )

(Fig. 2C), some of which appeared as rod-shape (Fig. 2D). The particles were positive for Warthin-Starry staining (Fig. 2E) and negative for acid-fast staining (Fig. 2F). In the biopsy specimens obtained three months after treatment, swollen villi were still present (Fig. 2G), as were PASpositive particles in the macrophages (Fig. 2H).

\section{PCR analysis of Tropheryma whipplei 16S rDNA}

Template DNA was extracted from the FFPE specimens using the DNeasy Blood and Tissue Kit (QIAGEN, K.K., Tokyo, Japan). Briefly, five slices of paraffin sections were deparaffinized with xylene and ethanol. The sections were completely lysed in the ATL buffer with proteinase $\mathrm{K}$ at 56 ${ }^{\circ} \mathrm{C}$ and DNA was extracted using standard protocol. T. whipplei $16 \mathrm{~S}$ rDNA was amplified with the primers reported by 
Tropheryma whipplei $16 \mathrm{~S}$ rDNA Gene Based on complete genome sequence (AE014184)

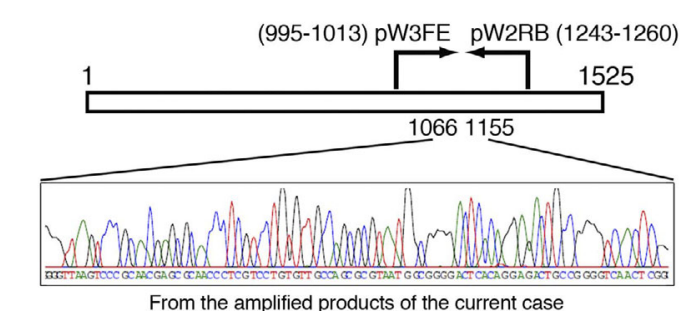

From the amplified products of the current case

B

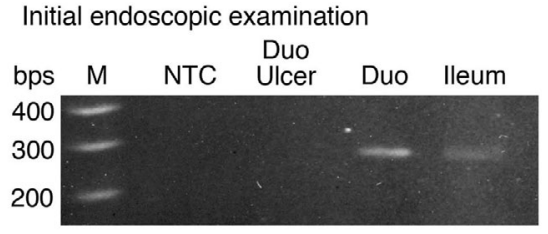

C

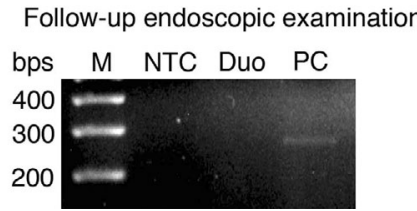

Figure 3. A PCR analysis of 16S rDNA of Tropheryma whipplei. (A) Tropheryma whipplei $16 \mathrm{~S}$ rDNA and the sequence of the amplified product in the current case. (B) Amplification of 16S rDNA in the biopsy specimens obtained during the initial endoscopic examination. bps: base pairs, M: marker, NTC: no template control, Duo: duodenum. (C) PCR amplification in the specimens obtained during the follow-up endoscopic examination performed three months after treatment. PC: positive control of ileum obtained during the initial endoscopic examination.

Relman (3): the forward primer was pW3FE: 5'-AGA GAT ACG CCC CCC GCA A-3' and the reverse primer was pW 2RB: 5'-ATT CGC TCC ACC TTG CGA-3' (Fig. 3A). The PCR mixture consisted of $50 \mu \mathrm{L}$ of $1 \mathrm{X}$ PCR buffer, $1.5 \mathrm{mM}$ $\mathrm{MgCl}_{2}, 0.2 \mathrm{mM}$ dNTPs, $200 \mathrm{nM} \mathrm{pW} 3 \mathrm{FE}$ and pW2RB, $1 \mathrm{U}$ AmpliTaq Gold (Applied Biosystems, Inc., Tokyo, Japan) and $50 \mathrm{ng}$ of extracted DNA as the template. The PCR reaction was with initial denaturation at $96^{\circ} \mathrm{C}$ for 10 minutes followed by 40 cycles at $96^{\circ} \mathrm{C}$ for one minute, $55^{\circ} \mathrm{C}$ for one minute and $72^{\circ} \mathrm{C}$ for one minute. Final extension was then completed at $72^{\circ} \mathrm{C}$ for seven minutes. The PCR products were electrophoresed in a 3\% agarose gel.

A single band was amplified from the duodenum and ileum taken during the initial endoscopic examination (Fig. 3B). No amplification was obtained in another controlled case of duodenal ulcers. The amplified product was 266 base pairs in length, and the sequence was homologous to the sequence of T. whipplei 16S rDNA in GenBank (AE 014184) (Fig. 3A). No amplification was observed in the sample taken three months after treatment (Fig. 3C).

$\overline{\text { Discussion }}$

Making a definitive diagnosis of WD requires confirmation of $T$. whipplei on immunostaining, electron microscopy or a PCR analysis of the microorganism's genes (2). Culturing the bacterium is difficult, with only a limited number of facilities successfully performing the process worldwide. Conducting a histological examination in combination with special stains is necessary to exclude infections by other microorganisms. The Warthin-Starry method positively stained the bacilli in the current case. Acid-fast staining is necessary to differentiate WD from mycobacterial infection because some species, such as Mycobacterium intracellulare and $M$. genavense, are positive for PAS (4). The use of immunostaining for T. whipplei in order to make a diagnosis has been reported in the literature (5); however, antibodies are not available for routine diagnosis. An electron microscopic examination was not performed in this case because it takes a long time for diagnosis.

The PCR method we employed to amplify T. whipplei gene is rapid, specific and sensitive. To date, fresh biopsy samples have commonly been used for PCR analyses. It has also been shown that the sensitivity of PCR using FFPE specimens is comparable to that using fresh tissues (6). With the use of the primer set specific to T. whipplei (3), the fragment of T. whipplei $16 \mathrm{~S}$ rDNA was successfully amplified in the current case. The amplified products were confirmed to be homologous to T. whipplei based on sequencing, thus negating a false-positive reaction with other microorganisms (7). In the current case, although both the duodenum and ileum were affected, the ileal mucosa showed a more pronounced expression of swollen villi. Biopsy specimens obtained during endoscopic examinations are usually fixed in formalin immediately after sampling. Even when WD is suspected in an FFPE biopsy specimen, it is not always feasible to repeat an endoscopic examination of the lower gastrointestinal tract for sampling of fresh tissue from the ileum. Therefore, the use of FFPE specimens for PCR analyses should be considered in the retrospective evaluation and diagnosis of WD.

Only five Japanese cases, including the current case, have been reported in the literature (Table) (8-11). Nine additional cases were reported in the form of abstracts (12-20). Most of the patients were in the fifth decade of life and presented with weight loss, diarrhea, fever and arthralgia. In three cases, the diagnosis of WD was confirmed on electron microscopy $(8,9,11)$. In one case, the diagnosis was confirmed at autopsy. A PCR analysis using fresh tissue was applied in one case (9), while the current case is the first Japanese case diagnosed with PCR using FFPE specimens. The disease was diagnosed more than six months after the patient presented with symptoms. In the current case, the diagnosis was obtained with PCR using FFPE specimens, and antibiotic treatment was immediately initiated. To prevent CNS involvement, prompt diagnosis and early initiation of 
Table. Japanese Cases of Whipple Disease

\begin{tabular}{|c|c|c|c|c|c|c|c|c|}
\hline Authors & Age/Sex & Symptoms & Precedent symptoms & Affected organs & Background & $\begin{array}{l}\text { Diagnostic modality } \\
\text { (site of sample) }\end{array}$ & Treatment & Prognosis \\
\hline Naramoto (8) & $45 / \mathrm{M}$ & $\begin{array}{l}\text { Diarrhea } \\
\text { LN swelling }\end{array}$ & Arthralgia (10 years) & $\begin{array}{l}\text { GI, Heart, Joints, } \\
\text { LNs }\end{array}$ & Abroad & $\begin{array}{l}\text { PAS, EM (negative) } \\
\text { (Jejunum) }\end{array}$ & Tetracycline & AW (2 months) \\
\hline Yogi (9) & $52 / \mathrm{M}$ & $\begin{array}{l}\text { Weight loss, } \\
\text { Edema }\end{array}$ & Diarrhea (16 months) & GI & HTLV-1 (+) & $\begin{array}{l}\text { PAS, EM, PCR } \\
\text { (Duodenum) }\end{array}$ & $\begin{array}{l}\text { CTRX } \\
>\text { TMP/SMZ }\end{array}$ & AW (15 months) \\
\hline Kawasaki (10) & $54 / \mathrm{M}$ & $\begin{array}{l}\text { Weight loss } \\
\text { (10 kg/6 months) }\end{array}$ & Diarrhea (6 months) & GI, LNs & HTLV-1 (+) & $\begin{array}{l}\text { PAS (Duodenum, } \\
\text { Ileum, colon) }\end{array}$ & $\begin{array}{l}\text { CTRX } \\
>\text { TMP/SMZ }\end{array}$ & AW (30 months) \\
\hline Tsuru (11) & $56 / \mathrm{M}$ & Diarrhea & Weight loss ( 2 years $)$ & $\begin{array}{l}\text { GI, Heart, Joints, } \\
\text { LNs }\end{array}$ & nd & $\begin{array}{l}\text { PAS, EM } \\
\text { (Duodenum, Ileum, } \\
\text { Colon) }\end{array}$ & Observation & DOD (2 years) \\
\hline Current case & $54 / \mathrm{F}$ & $\begin{array}{l}\text { Fever, Diarrhea } \\
\text { Arthralgia }\end{array}$ & $\begin{array}{l}\text { Weight loss } \\
(6 \mathrm{~kg} / 6 \text { months })\end{array}$ & $\begin{array}{l}\text { GI, Joints, LNs, } \\
\text { Spleen }\end{array}$ & Abroad & $\begin{array}{l}\text { PAS, PCR (FFPE) } \\
\text { (Duodenum, Ileum) }\end{array}$ & $\begin{array}{l}\text { CTRX } \\
>\text { TMP/SMZ }\end{array}$ & AW (2 years) \\
\hline
\end{tabular}

M: male, F: female, GI: gastrointestinal tract, LN: lymph node, HTLV-1: human T lymphotrophic virus-1, PAS: periodic acid Schiff, EM: electron microscope, CTRX: ceftriaxone, TMP: trimethoprim, SMZ: sulfamethoxazole, AW: alive well, DOD: died of disease, nd: not described

antibiotic treatment are essential. Performing pathological examinations combined with PCR analyses of FFPE specimens may therefore be of significant value in preventing delay in diagnosis.

Although the treatment regimen remains controversial (2), the current standard is to initiate CTRX for two weeks followed by TMP/SMZ for at least one year. PAS-positive particles remain in the cytoplasm of macrophages for several months, even when antibiotic treatment is effective (21). A PCR analysis is used to evaluate the efficacy of antibiotics, although obtaining negative results in a PCR analysis does not necessarily indicate eradication of a microorganism (21). The continued presence of PAS-positive particles in macrophages may indicate a risk of CNS relapse. Although no neurological symptoms are evident in the current case two years after treatment, careful long-term follow-up is required.

The authors state that they have no Conflict of Interest (COI).

\section{References}

1. Whipple GH. A hitherto undescribed disease characterized anatomically by deposits of fat and fatty acids in the intestinal and mesenteric lymphatic tissues. Johns Hopkins Hosp Bull 18: 382391, 1907.

2. Schneider T, Moos V, Loddenkemper C, et al. Whipple's disease: new aspects of pathogenesis and treatment. Lancet Infect Dis 8: 179-190, 2008.

3. Relman DA, Schmidt TM, MacDermott RP, Falkow S. Identification of the uncultured bacillus of Whipple's disease. N Engl J Med 327: 293-301, 1992

4. Dutly F, Altwegg M. Whipple's disease and "Tropheryma whippelii”. Clin Microbiol Rev 14: 561-583, 2001.

5. Baisden BL, Lepidi H, Raoult D, et al. Diagnosis of Wihipple disease by immunohistochemical analysis: a sensitive and specific method for the detection of Tropheryma whipplei (the Whipple bacillus) in paraffin-embedded tissue. Am J Clin Pathol 118: 742748, 2002.

6. Lynch T, Odel J, Fredericks DN, et al. Polymerase chain reactionbased detection of Tropheryma whippelii in central nervous system
Whipple's disease. Ann Neurol 42: 120-124, 1997.

7. Rolain JM, Fenollar F, Raoult D. False positive PCR detection of Tropheryma whipplei in the saliva of healthy people. BMC Microbiol 7: 48, 2007.

8. Naramoto J, Tamechika Y, Niizeki H, et al. A case of Wipple disease with non-specific multiple ulcer of the intestine. Stomach and Intestine 11: 227-231, 1976 (in Japanese).

9. Yogi T, Hokama A, Kinjo F, et al. Whipple's Disease: the First Japanese case diagnosed by electron microscopy and polymerase chain reaction. Intern Med 43: 566-570, 2004.

10. Kawasaki K, Kobayashi H, Kurahara K, et al. Whipple's disease with findings of NBI magnifying observation and capsule endoscopy, report of a case. Stomach and Intestine 46: 311-319, 2011 (in Japanese).

11. Tsuru T, Hamada T, Honda M, et al. An autopsy case of Whipple disease. Saishin Igaku 34: 1993-1997, 1979 (in Japanese).

12. Morishita A. A case of Whipple disease. J Jpn Pediatr Soc 90: 2816, 1986 (Abstract in Japanese).

13. Suehara M, Niiyama T, Higuchi I, et al. The first Japanese case of CNS Whipple's disease. Clinical Neurology 39: 252, 1999 (Abstract in Japanese).

14. Minagawa K, Aramaki K, Kikuchi H, et al. A case of Whipple disease with clincal features of polyarteritis nodosa. Ryumachi $\mathbf{4 3}$ : 464, 2003 (Abstract in Japanese).

15. Nimura S, Uesugi N, Kuramochi H, et al. A case of Whipple disease with concurrent lymphoma of small intestine. Proc Jpn Soc Pathol 94: 267, 2005 (Abstract in Japanese).

16. Iwamura S, Uchita K, Kono N, et al. A Japanese case of Whipple disease diagnosed by immunohistochemistry. Nihon Shokakibyo Gakkai Zasshi 103: A839, 2006 (Abstract in Japanese).

17. Matsuda I, Imai $Y$, Tomita $T$, et al. A suspected case of Whipple disease. Proc Jpn Soc Pathol 96: 250, 2007 (Abstract in Japanese).

18. Chinen H, Nakamura M, Kurisutensen M, et al. A case of Whipple disease with difficulty in differential diagnosis with retroperitoneal tumor. Nihon Shokakibyo Gakkai Zasshi 105: A249, 2008 (Abstract in Japanese).

19. Uryu K, Sakai T, Hasegawa $Y$, et al. A review of treatment course of a case of Whipple disease recurred by symptoms of central nervous system. Nihon Naika Gakkai Zasshi 98: 121, 2009 (Abstract in Japanese).

20. Yao A, Ooya S, Higo H, et al. A case of Whipple disease. Gastroenterological Endoscopy 51: 828, 2009 (Abstract in Japanese).

21. von Herbay A, Ditton HJ, Maiwald M. Diagnostic application of a polymerase chain reaction assay for the Whipple's disease bacterium to intestinal biopsies. Gastroenterology 110: 1735-1743, 1996.

(C) 2013 The Japanese Society of Internal Medicine http://www.naika.or.jp/imonline/index.html 